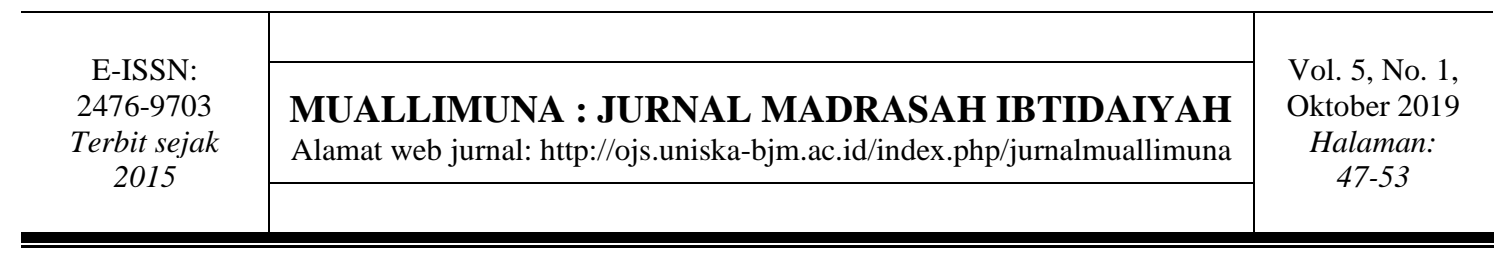

\title{
STUDI KASUS TENTANG KREATIVITAS GURU PADA PEMBELAJARAN TEMATIK INTEGRATIF DI SD ANAK SALEH MALANG
}

\author{
Delila Sari Batubara \\ STAI Barumun Raya Sibuhuan \\ delilasari23@gmail.com
}

\begin{abstract}
Abstrak: Penerapan pembelajaran tematik integratif dalam kurikulum 2013 memerlukan kreatifitas guru dalam merancang, mengelola dan mengevaluasi kegiatan pembelajaran. Penelitian ini bertujuan untuk mengetahui bagaimana kreativitas guru pada pembelajaran tematik integratif, faktor-faktor dan upaya untuk meningkatkan kreativitas guru pada pembelajaran tematik integratif. Penelitian ini menggunakan pendekatan kualitatif dengan jenis studi kasus di Kelas 1 SD Anak Saleh Malang. Instrumen penelitian ini adalah observasi, wawancara, dan dokumentasi. Teknik analsis data yang digunakan adalah reduksi data, penyajian data, dan verifikasi. Hasil penelitian menemukan bahwa kreativitas guru dalam proses pembelajaran tematik integratif di kelas I SD Anak Saleh Malang cukup baik, karena pada umumnya guru kelas telah mampu membuat rencana pembelajaran yang kreatif, melaksanakan kegiatan pengajaran dengan baik, dan mengembangkan berbagai bentuk evaluasi pembelajan yang yang bervariasi. Faktor pendukung kreatifitas guru dalam pembelajaran adalah; keaktifan guru dalam komunitas profesi dan mengikuti kegiatan pelatihan, motivasi berprestasi, dan rekan kerja guru yang ramah dan peduli, dan kelengkapan sarana pembelajaran di sekolah. Adapun faktor penghambat kreativitas guru adalah: pendidikan guru kelas yang tidak linier, kurangnya penghargaan dari atasan, dan kesejahteraan guru yang masih minim. Adapun upaya sekolah untuk meningkatkan kreativitas guru dalam pembelajaran tematik adalah: mengembangkan kompetensi guru, mendorong guru untuk studi lanjut, memberikan supervisi yang intensif, dan menciptakan iklim kerja yang kondusif.
\end{abstract}

\section{Kata Kunci: Kreativitas Guru, Pembelajaran Tematik Integratif}

\section{A CASE STUDY ON TEACHER CREATIVITY IN INTEGRATIVE THEMATIC LEARNING IN ELEMENTARY SCHOOL ANAK SALEH MALANG}

\begin{abstract}
The implementarion of integrative thematic learning in the curriculum 2013 requires teacher creativity in designing, managing and evaluating learning activities. This study aims to find out how the teacher's creativity in integrative thematic learning, factors and efforts to improve teacher creativity in integrative thematic learning. This study used a qualitative approach with the type of case study at first classroom of Elementary School Anak Saleh Malang. The instruments were observation, interviews, and documentation. The technique of data analysis used were reduction, display, and verification.The results of the study found that the teacher's creativity in the integrative thematic learning process at first class of Elementary School Anak Saleh Malang is quite good, because in general the classroom teacher has been able to make creative learning plans, carry out teaching activities well, and develop various forms of learning evaluation that vary. Factors supporting teacher creativity in learning are; teacher activity in the
\end{abstract}


professional community and participating in training activities, achievement motivation, and friendly and caring teacher work colleagues, and complete learning facilities at school. The inhibiting factors of teacher creativity are: class teacher education that is not linear, lack of appreciation from superiors, and teacher welfare which is still minimal. The school's efforts to increase teacher creativity in thematic learning are: developing teacher competencies, encouraging teachers for further study, providing intensive supervision, and driving a conducive work atmosphere.

\section{Keywords: Teacher Creativity, Integrative Thematic Learning}

\section{PENDAHULUAN}

Kurikulum 2013 telah memberikan ruang yang semakin besar kepada guru untuk mendesain sistem pembelajaran dengan suasana yang menantang, memotivasi, dan menyenangkan. Dalam hal ini, kreativitas menjadi faktor yang sangat penting dalam pembelajaran yang berorientasi pada keterampilan abad 21. Oleh karena itu, guru harus menggunakan cara-cara yang kreatif dan inovatif dalam mengajar agar dapat melatih peserta didik untuk berpikir kreatif. Kreativitas berfungsi untuk membantu guru dalam menyelesaikan pekerjaannya dengan cepat dan efisien. Adapun pentingnya kreativitas guru dalam pembelajaran adalah: 1) Kreativitas guru berguna dalam transfer informasi lebih utuh, 2) Kreativitas guru berguna dalam merangsang siswa untuk lebih berpikir secara ilmiah dalam mengamati gejala masyarakat atau gejala alam yang menjadi objek kajian dalam belajar, dan 3) Produk kreativitas guru akan merangsang kreativitas siswa. Pembelajaran tematik-integratif dinilai lebih efektif dalam melatih dan mengembangkan kreatifiitas guru, karena dalam pembelajaran tematik-integratif guru harus mendorong siswa agar turut aktif dalam proses pembelajaran. Guru harus berusaha memberikan pengalaman belajar yang berarti bagi siswa sehingga siswa mampu mengasosiasi pengetahuan dan pengalaman yang mereka miliki dengan pengalaman baru yang mereka peroleh di sekolah. Oleh karena itu pembelajaran tematik integratif dalam implementasinya, membutuhkan guru kreatif, yaitu guru yang memiliki berbagai konsep dan cara untuk mendongkrak kualitas pembelajaran dengan menyediakan lingkungan yang kondusif, dan iklim pembelajaran yang demokratis

Salah satu masalah pendidikan di Indonesia adalah rendahnya kreativitas guru. Pernyataan tersebut di dukung oleh hasil penelitian Wahyu (2006) yang menyatakan bahwa tingkat kreativitas guru dalam pengelolaan sumber belajar dan pembuatan media pembelajaran masih rendah. Dalam jurnal yang ditulis oleh Srinalia (2015) menyatakan bahwa guru masih menggunakan metode yang monoton, dan belum banyak melakukan inovasi dalam proses pembelajaran. Sementara itu Kholid A. Harras dalam artikelnya mengungkapkan kreativitas masih barang langka di lingkungan guru. Langkanya kreativitas guru dapat dilihat dari masih rendahnya partisipasi dan keterlibatan guru dalam kegiatan lomba kreativitas, Sebagai contoh menurut informasi partisipasi guru Bahasa Indonesia SMA dan sederajat yang mengikuti LMKS (Lomba Mengulas Karya Sastra) dan LMCP (Lomba Menulis Cerita Pendek) yang diadakan oleh Dikdasmen setiap tahun rata-rata hanya diikuti oleh sekitar 200 -an orang guru saja. Padahal jumlah guru bahasa Indonesia yang mengajar di SMA dan sederajat (SMK dan MA), baik negeri maupun swasta di negeri ini telah mencapai ribuan orang. Dari beberapa hasil penelitian daiatas telah mengungkapkan rendahnya kreativitas guru dalam pembelajaran. SD Anak Saleh Malang adalah salah satu Sekolah Dasar tersebut yang terletak di kota Malang yang 
merupakan salah satu sekolah yang sangat berprestasi. Sekolah ini telah banyak meraih prestasi, baik di tingkat Nasional dan juga di tingkat Internasional, seperti: Bronze Medal (Olimpiade Sains Kuark Jakarta), Bronze Medal (Internasional Mathematic and sains olimpiade Bali-Indonesia), Pada tahun 2016 Juara umum Green school festival SD Non adiwiyata, Juara Harapan pada ajang perlombaan Best Of The Best (Internasional Drawing \& Colouring Kuala Lumpur Malaysia dan New Delhi India dan menjadi Host of School Visit ICLS 2016. Hasil wawancara dengan Bapak Andre selaku wakil kepala sekolah bidang akademik di SD Anak Saleh diperoleh informasi bahwa guru-guru di sekolah tersebut memiliki kreatiftas yang baik. Peneliti memandang perlu diadakannya penelitian lebih lanjut tentang "kreativitas guru pada pembelajaran tematik integratif di SD Anak Saleh Malang" baik dari sisi tindakan, motif, dan dampaknya.

Untuk mendeskripsikan dan menganalisis kreativitas guru pada pembelajaran tematik integratif, maka peneliti membuat fokus penelitian, yaitu bagaimana kreativitas guru pada pembelajaran tematik integratif, faktor yang mempengaruhi dan upaya untuk meningkatkan kreativitas guru pada pembelajaran tematik integratif.

Dalam penelitian ini yang dimaksud dengan kreativitas guru adalah kemampuan guru untuk menghasilkan cara-cara-cara baru dalam proses pengajaran maupun mengembangkan hal-hal yang sudah ada sebelumnya serta bisa memodifikasi pembelajaran sehingga dapat menarik perhatian siswa dalam kegiatan belajar mengajar. Selanjutnya pembelajaran tematik integratif adalah pembelajaran yang mengintegrasikan mata pelajaran atau sub tema mata pelajaran kedalam sebuah tema. Sebagaimana disampaikan Sutijo dan Sri Istuti Mamik, pembelajaran tematik-integratif adalah pembelajaran yang mengintegrasikan materi beberapa mata pelajaran dalam satu tema pembahasan. Pembelajaran tematik-integratif akan memicu kreativitas guru karena dalam pembelajaran tematik-integratif guru harus mendorong siswa agar turut aktif dalam proses pembelajaran. Guru harus berusaha memberikan pengalaman belajar yang berarti bagi siswa sehingga siswa mampu mengasosiasi pengetahuan dan pengalaman yang mereka miliki dengan pengalaman baru yang mereka peroleh di sekolah.

\section{METODE}

Dalam penelitian ini, peneliti menggunakan pendekatan kualitatif, dengan jenis studi kasus. Teknik pengumpulan data yang digunakan adalah observasi, wawancara, dan dokumentasi yang kemudian diolah berdasarkan dengan teknik reduksi data, penyajian data, dan verifikasi.

Latar penelitian ini dilakukan di SD Anak Saleh Malang. Peneliti berfungsi sebagai instrument kunci sekaligus sebagai pengumpul data, maka di dalam upaya untuk memperoleh data yang dibutuhkan, peneliti berperan sebagai pengamat penuh, artinya peneliti disamping sebagai pengamat juga ikut berbaur dengan responden, sehingga terbina hubungan kerja sama dan memberi kemudahan di dalam pengumpulan data informasi yang diperlukan.

Dalam penelitian ini, data primer yang akan digunakan oleh peneliti yaitu berupa data verbal dari hasil wawancara dengan para informan yang kemudian peneliti catat dalam bentuk catatan tertulis, rekaman dengan recorder handphone, serta pengambilan foto dengan camera hanphone. Sedangkan data dari pengamatan langsung (observasi) akan peneliti catat dalam bentuk catatan lapangan. Adapun teknik pengumpulan datanya menggunakan observasi, wawancara dan dokumentasi. Peneliti menggunakan teknik analisis data Lexi J Moleong dan Sugiyono dengan teknik reduksi data, penyajian data, 
dan verifikasi. Pengecekan keabsahan data menggunakan triangulasi data dan pengecekan.

\section{HASIL DAN PEMBAHASAN \\ Kreativitas Guru Pada Pembelajaran Tematik Integratif}

Dari temuan peneliti untuk menjawab fokus penelitian pertama yaitu kreativitas guru pada pembelajaran tematik integratif di kelas I SD Anak Saleh Malang cukup baik, karena pada umumnya guru kelas telah mampu membuat rencana pembelajaran yang kreatif, yaitu dokumen rencana pembelajaran yang dibuat guru merupakan hasil pengembangan guru yang dihasilkan melalui proses pemikiran yang benar dan dan menggunakan berbagai sumber yang ada untuk menghasilkan sebuah rencana pembelajaran yang berbeda dengan yang sudah ada. Perencanaan pembelajaran, yang meliputi; perumusan indikator dan tujuan pembelajaran, penetapan alur kegiatan belajar mengajar, penetapan metode pembelajaran yang bervariasi, pemilihan dan perancangan alat peraga atau media pembelajaran, dan pembuatan lembar kerja siswa yang menarik dan menantang.

Selanjutnya guru mampu melaksanakan kegiatan pengajaran dengan baik yang meliputi; penyampaian materi pelajaran dengan interaktif, penggunaan metode/teknik mengajar yang bervariasi, penggunaan media dan alat pelajaran yang relevan, dan penciptaan interaksi belajar mengajar di kelas dan di sekolah alam dengan baik. sehingga tercipta sebuah model pembelajaran yang efektif dalam melayani berbagai kebutuhan siswa dan guru mampu mengembangkan berbagai bentuk evaluasi pembelajaran yang yang bervariasi dan pelaksanaan evaluasi pembelajaran yang otentik.

\section{Faktor-faktor yang mempengaruhi kreativitas Guru}

Pada fokus penelitian yang kedua yaitu faktor-faktor yang mempengaruhi kreativitas guru pada pembelajaran tematik integratif ada dua faktor yaitu faktor pendukung dan faktor penghambat, Adapun faktor pendukungnya adalah a) keaktifan guru dalam komunitas profesi karena Keaktifan guru dalam berbagai kegiatan akademik, organisasi profesi, dan pelatihan di bidang pendidikan akan mengembangkan wawasan dan keterampilan guru. Dengan wawasan dan keterampilan tersebut maka guru akan mendorong dan guru untuk kreatif dalam mengatasi persoalan yang dihadapinya dan mengembangkan kemampuannya secara berkelanjutan. b) rekan kerja guru yang ramah dan peduli, Suasana kerja yang kondusif akan membuat seseorang merasa aman dan mencintai lembaganya sehingga hal tersebut akan mendorong guru untuk memberikan sesuatu yang terbaik atau membanggakan bagi lembaganya..c)kelengkapan sarana pembelajaran, Sekolah Dasar Anak Saleh memiliki fasilitas belajar yang baik yaitu perpustakaan, mesjid, dan sekolah alam. Ketersediaan fasilitas yang lengkap dapat mendorong guru untuk kreatif dalam memanfaatkan lingkungan sekolah sebagai sarana belajar.,d)Motivasi berprestasi, salah satu hal yang mempengaruhi kreativitas guru adalah komitmen guru dalam mengabdi. Selain itu motivasi berprestasi mendorong guru untuk selalu belajar meningkatkan cara mengajarnya. Sedangkan faktor penghambat kreativitas guru adalah: a) pendidikan guru kelas yang tidak linier, pendidikan formal diyakini memberikan pengaruh bagi tingkat kreativitas guru. Melalui pendidikan formal dan kegiatan penelitian guru akan memiliki sejumlah ilmu pengetahuan yang mendorongnya untuk kreatif dalam memahami dan menyelesaikan permasalahan yang dihadapinya. b) kurangnya penghargaan dari atasan, penghargaan dari atasan sangat bermanfaat dalam memancing dan mendorong guru untuk kreatif dan berprestasi. Tanpa penghargaan dan dorongan dari atasan maka guru biasanya akan malas untuk 
menunjukkan kreativitasnya. c) kesejahteraan guru, Kesejahteraan guru mempengaruhi kreativitas guru Kesejahteraan sebagai imbalan diyakini juga menjadi faktor penting yang dapat mendorong kreativitas guru dan semangat guru.

\section{Upaya Sekolah Untuk Meningkatkan Kreativitas Guru}

Pada fokus penelitian yang ketiga yaitu upaya sekolah untuk meningkatkan kreativitas guru dalam pembelajaran tematik integratif adalah: a) mengembangkan kompetensi guru. Pengembangan kompetensi guru di SD Anak Saleh dilakukan melalui pemberian kesempatan dan kebebasan kepada guru untuk berkreasi menggunakan berbagai sarana sekolah dan mengikut sertakan guru terpilih dalam berbagai kegiatan pelatihan dan perlombaan. b)mendorong guru untuk studi lanjut, memberikan supervisi yang intensif, c) memberikan supervise yang intensif dan c)menciptakan iklim kerja yang kondusif. Upaya untuk menciptakan iklim yang menyenangkan di sekolah adalah dengan memupuk rasa persaudaraan guru melalui kegiatan wisata bersama, outbound, dan rapat penyelesaian masalah.

\section{PENUTUP}

Berdasarkan penjelasan di atas, maka kesimpulan dari artikel ini adalah sebagai berikut.

1. Kreativitas guru dalam proses pembelajaran tematik integratif di kelas I SD Anak Saleh Malang cukup baik, karena pada umumnya guru kelas telah dapat membuat dan melakukan perencanaan pembelajaran, pengelolaan pelaksanaan pengajaran dengan baik, dan pelaksanakan evaluasi pembelajan yang otentik, motivatif, edukatif, dan menggunakan bentuk-bentuk penilaian yang bervariasi.

2. Faktor-faktor yang mempengaruhi kreativitas guru dalam pembelajaran tematik integraif di SD Anak Saleh Malang terdiri dari factor pendukung dan factor penghambat. Faktor pendukungnya adalah: 1) keaktifan guru dalam komunitas profesi dan mengikuti kegiatan pelatihan membuat guru memiliki keterampilan yang baik dalam menggunakan berbagai macam sumber belajar, mengkombinasikan berbagai metode pembelajaran, mengelola kelas, dan menggunakan bentuk-bentuk penilaian yang bervariasi. 2) Motivasi berprestasi mendorong guru untuk selalu belajar meningkatkan cara mengajarnya, 3) Rekan kerja guru yang ramah dan peduli terhadap dirinya menjadikan guru semangat dalam kebersamaan, 4) Kelengkapan sarana pembelajaran menjadi faktor yang mendorong guru untuk menyalurkan kreatifitasnya dalam mengelola kegiatan pembelajaran yang menarik. Adapun faktor penghambatnya adalah: 1) pendidikan guru kelas yang tidak linier, 2) kurangnya penghargaan dari atasan, 3) dan faktor kesejahteraan guru.

3. Adapun upaya yang telah dilakukan sekolah untuk meningkatkan kreativitas guru dalam pembelajaran tematik di SD Anak Saleh Malang adalah: mengembangkan kompetensi guru, mendorong guru untuk studi lanjut, memberikan supervisi yang intensif, dan menciptakan iklim kerja yang kondusif. 


\section{DAFTAR PUSTAKA}

Abidin, Yunus. (2012). Model Penilaian Otentik Dalam Pembelajaran Membaca Pemahaman Beroreintasi Pendidikan Karakter, (Jurnal Pendidikan Karakter, No. 2 edisi Juni 2012.

Akbar, Reni Hawadi, et.al, Kreativitas, 2001. (Jakarta: Grasindo).

Alfiani. (2010). Kreativitas Guru Dalam Memotivasi siswa Pada Pembelajaran Pendidikan Agama Islam di SMPN 20 Tangerang (Skripsi), Fakultas Ilmu Tarbiyah dan Keguruan Universitas Islam Negeri Syarif Hidayatullah Jakarta.

Arikunto, Suharsimi. (2006). Prosedur Penelitian: Suatu Pendekatan Praktik, Jakarta: Rineka Cipta.

Bungin, Burhan. (2003). Analisa Data Penelitian Kualitatif. Jakarta: PT. Raja Grafindo Persada.

Cambell, David. (1986). Mengembangkan kreativitas. Yogyakarta: Kansius.

Dep. Pend. dan Kebudayaan. (2003). Kamus Besar Bahasa Indonesia. Jakarta: Balai Pustaka.

Emzir. (2012). Metodologi Penelitian Kualitatif Analisis Data. Jakarta: Rajawali Pers.

Caesar, F. T. (2014). Kreativitas Guru SD Dan Kuasa Kurikulum Dalam Penerapan Kurikulum 2013. Jurnal Mahasiswa Sosiologi, 2(2).

Fatma Desi Ratih. (2009). Pengembangan Kreativitas Mengajar Guru dalam Memotivasi Siswa Pada Pembelajaran PKN. Skripsi. Semarang: Universitas Negeri Semarang.

Hasnawati. (2013). Sistem Pembelajaran Terpadu Di Sekolah, Marwah, 12 (1).

Hawadi Akbar Reni. (2001). Kreativitas, Jakarta: Grasindo

Jerner, David Martin. (2006). Elementary Science Methods: A Constructivist Approach, Fourth Edition, USA: Thomson Wadsworth.

K.Yin Robert. (2015) Studi Kasus Desain dan Metode. Jakarta: Raja Grafindo Persada.

Khuzaifah. (2015). Kreativitas Guru Dalam Menerapkan Kurikulum 2013 Melalui Model Discovery Learning Pada Pembelajaran Fikih Kelas VII Di MTs Negeri Bantul Kota. Skripsi. Yogyakarta: Fakultas Ilmu Tarbiyah dan Keguruan UIN Sunan Kalijaga.

M. Hosnan. (2014). Pendekatan Saintifik dan Kontekstual dalam Pembelajaran Abad 21 Bogor: Ghalia Indonesia.

Majid Abdul. (2014). Implementasi Kurikulum 2013: Kajian Teoritis dan Praktis, Bandung: Interes Media.

Majid Abdul. (2014). Pembelajaran Tematik Terpadu (Bandung: PT. Remaja Rosdakarya.

Matsum, Junaidi H., et al., (2017). Analisis Kreativitas Guru dalam Proses Belajar Moleong, Lexy J., 2000. Metodologi Penelitian Kualitatif. Bandung: PT. Remaja Rosdakarya.

Mudiono, Alif dkk. (2016). Developing of Integrated Thematic Learning Model through Scientific Approaching with Discovery Learning Technique in Elementary School", International Academic Journal of Social Science, 3(10).

Oktavia Yanti. (2014). Usaha Kepala Sekolah Dalam Meningkatkan Kreativitas Guru Dalam Pembelajaran di Sekolah Dasar. Bahana Manajemen Pendidikan, 2(1), 808-815. 
Permendukbud No. 22 TAHUN 2016 tentang Standar Proses Pendidikan Dasar dan Menengah.

Srinalia. (2015). Faktor-faktor Penyebab Rendahnya Kinerja Guru Dan Korelasinya Terhadap Pembinaan Siswa. Jurnal Ilmiah Didaktika, 5(2).

Wahyu. (2006). Model Pengelolaan Sumber Belajar dan Media Pembelajaran Pada Guru Di Tingkat SMA se-Jawa Tengah. Dinas Pendidikan Kebudayaan provinsi Jawa Tengah 